Case Report

\title{
Reactive Eccrine Syringofibroadenoma on the Heel, Clinically Mimicking Squamous Cell Carcinoma
}

\author{
Yuri Sugita (D), Teruhiko Makino (D), Kotaro Matsui, and Tadamichi Shimizu \\ Department of Dermatology, Graduate School of Medicine and Pharmaceutical Sciences, University of Toyama, Toyama 930-0194, \\ Japan \\ Correspondence should be addressed to Tadamichi Shimizu; shimizut@med.u-toyama.ac.jp
}

Received 21 August 2019; Revised 1 November 2019; Accepted 6 November 2019; Published 4 December 2019

Academic Editor: Soner Uzun

Copyright (c) 2019 Yuri Sugita et al. This is an open access article distributed under the Creative Commons Attribution License, which permits unrestricted use, distribution, and reproduction in any medium, provided the original work is properly cited.

The authors present a case of eccrine syringofibroadenoma that clinically mimicked squamous cell carcinoma and briefly comment on the current knowledge about its clinical and histopathological features and therapeutic options.

\section{Introduction}

Eccrine syringofibroadenoma (ESFA) is a rare benign skin disease that originates from the eccrine ducts. First described by Mascaro in 1963 [1], ESFA is histologically characterized by anastomosing strands of epithelial cells embedded in a fibro-vascular stroma. However, despite its distinct histological manifestation, the clinical appearance of ESFA is nonspecific and variable. We herein report a case of reactive ESFA with hyperkeratosis and hematomas on the heel, clinically mimicking squamous cell carcinoma.

\section{Case Presentation}

A 90-year-old Japanese woman presented with a 4-year history of hyperkeratotic lesions on her left heel that had not been improved by topical treatment with salicylic acid petrolatum ointment or $10 \%$ urea cream. There was no history of trauma, but she gradually found it hard to walk because of her left heel pain. The patient had been taking clopidogrel, aspirin, azosemide, metformin hydrochloride, and alogliptin benzoate for the treatment of chronic heart failure, angina, and diabetes mellitus, and all of these symptoms had been well controlled. At the first visit, a clinical examination revealed an erythematous plaque with multiple brown macules, ulcer, and hyperkeratosis (Figure 1).

Dermoscopy demonstrated glomerular vessels with regular arrangement in the ulcer area (Figure 2(a)) and red-black homogeneous areas in the erythematous area (Figure 2(b)). She had no particular family history. Although we recommended that she undergo a skin biopsy to diagnose the skin lesion, the patient and her family expressed a strong desire to treat the lesion through a single surgical operation because she was at an advanced age, and the possibility of squamous cell carcinoma could not be completely excluded. Therefore, the skin lesion was totally excised.

The histopathological examination revealed hyperkeratosis and thin anastomosing strands of cuboidal cells extending from the epidermis to the upper dermis (Figure 3(a)). Small ductal structures and cystic changes were observed within the interconnected strands of cells. Hematomas were found in the intracorneal region and upper dermis (Figure 3(b)). No mitotic or dysplastic cells were observed. The cells of the ductal and cystic structures were positive for carcinoembryonic antigen (CEA) (Figures 3(c) and 3(d)). Based on these findings, the lesion was diagnosed as a reactive ESFA.

\section{Discussion}

ESFA is commonly classified into five subtypes: (i) solitary ESFA, (ii) multiple ESFA associated with hidrotic ectodermal dysplasia (Schöpf syndrome), (iii) multiple ESFA without associated cutaneous findings (eccrine syringofibroadenomatosis), (iv) non-familial unilateral linear ESFA (nevoid ES), and (v) reactive ESFA associated with an inflammatory or neoplastic process [2-4]. The present patient was diagnosed with reactive 


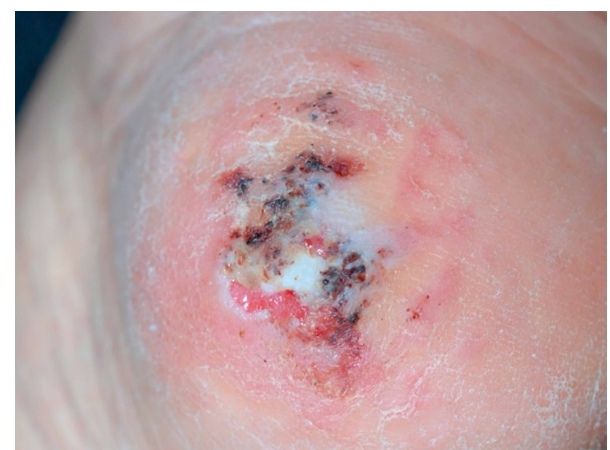

FIgURE 1: Clinical findings of the patient. Erythema plaque with multiple brown macules, ulcer, and hyperkeratinization on the left heel.

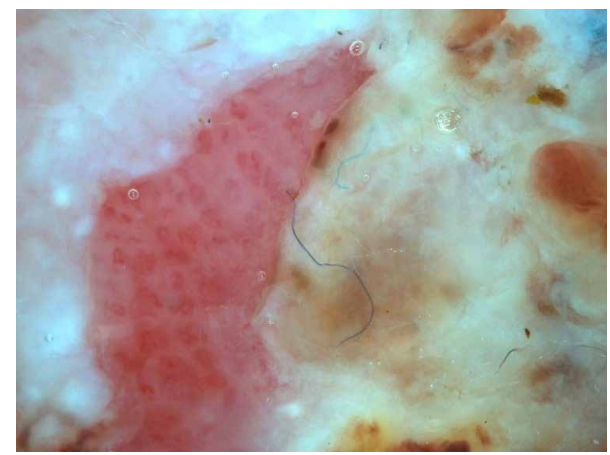

(a)

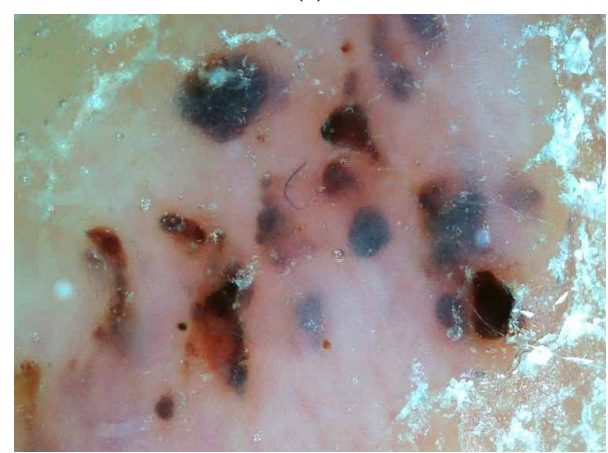

(b)

Figure 2: (a) Dermoscopy of the ulcer lesion. Glomerular vessels with regular arrangement in the ulcer area. (b) Dermoscopy of the erythematous plaque. There were features of intracorneal hemorrhaging.

ESFA based on the characteristic histological and immunohistochemical findings.

Reactive ESFA is associated with tissue remodeling and has been found together with erosive palmoplantar lichen planus [3], bullous pemphigoid [5], burn scar [6], lepromatous leprosy [7], diabetes mellitus with polyneuropathy and chronic ulcers [8], nevus sebaceous, or squamous cell carcinoma [9]. In the present patient, both chronic stimulation and repetitive ulceration may have been associated with the development of reactive ESFA. The lesion in the present patient demonstrated unique findings, such as hyperkeratosis, ulceration, and

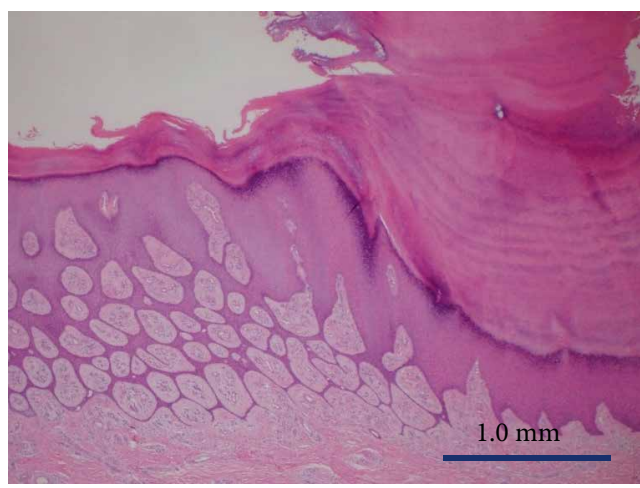

(a)

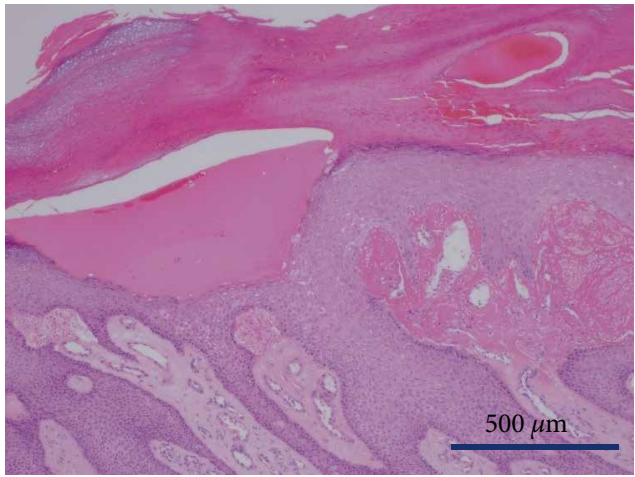

(b)

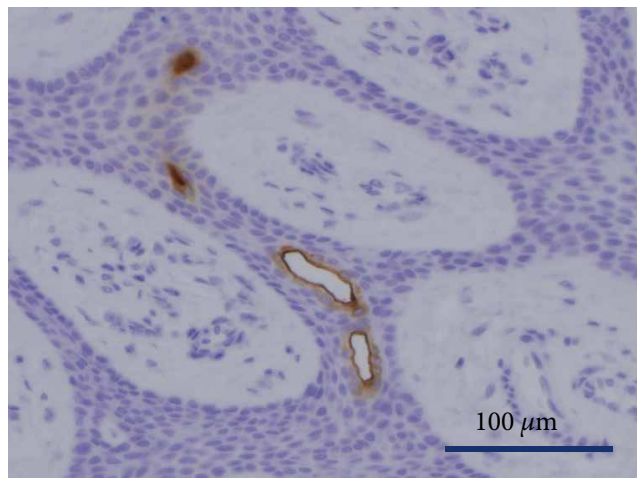

(c)

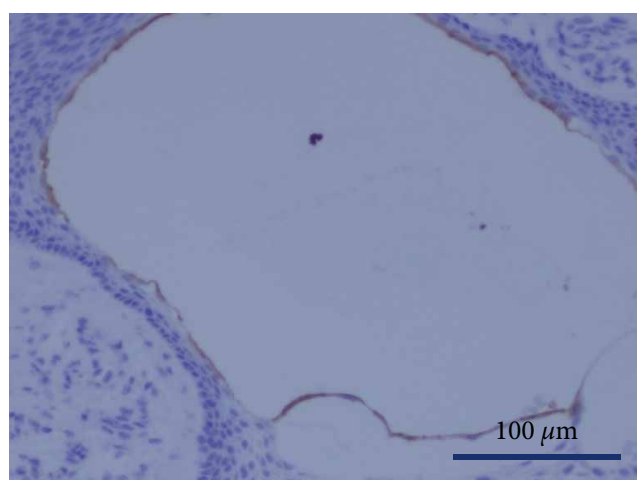

(d)

FIgURE 3: (a) Hyperkeratosis with thin anastomosing strands of cuboidal cells extending from the epidermis to the upper dermis $(\mathrm{H} \& \mathrm{E}$ stain, original magnification $\times 2$ ). (b) Hematomas in the intracorneal region and upper dermis ( $\mathrm{H} \& \mathrm{E}$ stain, original magnification $\times 4)$. (c) The cells of the ductal and cystic structures (d) were positive for CEA (original magnification $\times 20$ ) . 
hematomas. Although ESFA is well known to show a varied clinical appearance, no findings similar to ours have yet been reported. In addition, the clinical appearance in this case suggested the possibility of squamous cell carcinoma. Repetitive bleeding, which was enhanced by aspirin, may modify the clinical appearance.

In some subtypes of ESFA, malignant transformation into syringofibrocarcinoma or eccrine porocarcinoma has occasionally been observed [10]. However, reactive ESFA usually shows no malignant transformation; surgical excision may therefore be unnecessary for treating reactive ESFA, although the skin lesion in the present patient was totally excised. Reactive ESFA showing atypical findings may clinically resemble squamous cell carcinoma; therefore, physicians should consider reactive ESFA as a disease that should be distinguished from skin malignancy.

\section{Data Availability}

The data used to support the findings of this study are available from the corresponding author upon request.

\section{Consent}

The examination of the patient was conducted according to ICMJE guidelines.

\section{Conflicts of Interest}

The authors declare that there are no conflicts of interest regarding the publication of this article.

\section{References}

[1] J. M. Mascaro, "Considerations on fibro-epithelial tumors: exocrine syringofibroadenoma," Annals of Dermatology and Syphiligraphy, vol. 90, pp. 143-153, 1963.

[2] T. M. Starink, "Eccrine syringofibroadenoma: multiple lesions representing a new cutaneous marker of the Schöpf syndrome, and solitary nonhereditary tumors," Journal of the American Academy of Dermatology, vol. 36, no. 4, pp. 569-576, 1997.

[3] L. E. French, E. Masgrau, P. Chavaz, and J. H. Saurat, "Eccrine syringofibroadenoma in a patient with erosive palmoplantar lichen planus," Dermatology, vol. 195, no. 4, pp. 309-310, 1997.

[4] L. E. French, "Reactive eccrine syringofibroadenoma: an emerging subtype," Dermatology, vol. 195, no. 4, pp. 399-401, 1997.

[5] K. Nomura and I. Hashimoto, "Eccrine syringofibroadenomatosis in two patient with bullous pemphigoid," Dermatology, vol. 195, no. 4, pp. 395-398, 1997.

[6] E. Ichikawa, Y. Fujisawa, Y. Tateishi, S. Imakado, and F. Otsuka, "Eccrine syringofibroadenoma in a patient with a burn scar ulcer," British Journal of Dermatology, vol. 143, no. 3, pp. 591-594, 2000.

[7] H. L. Tey, W. S. Chong, and S. N. Wong, "Leprosy-associated eccrine syringofibroadenoma of Mascaro," Clinical and Experimental Dermatology, vol. 32, pp. 533-535, 2007.
[8] S. Thirawut, R. Salinee, and V. Vasanop, "Reactive eccrine syringofibroadenoma associated with neuropathy, venous stasis, and diabetic foot ulcer," Case Reports in Dermatology, vol. 8, no. 2, pp. 124-129, 2016.

[9] C. R. Schadt and A. S. Boyd, "Eccrine syringofibroadenoma with coexistent squamous cell carcinoma," Journal of Cutaneous Pathology, vol. 34, no. 1, pp. 71-74, 2007.

[10] T. Bjarke, A. Ternesten-Bratel, M. Hedblad, and A. Rausing, "Carcinoma and eccrine syringofibroadenoma: a report of five cases," Journal of Cutaneous Pathology, vol. 30, no. 6, pp. 382-392, 2003. 


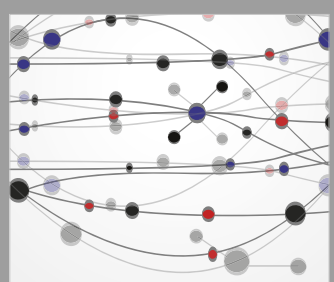

The Scientific World Journal
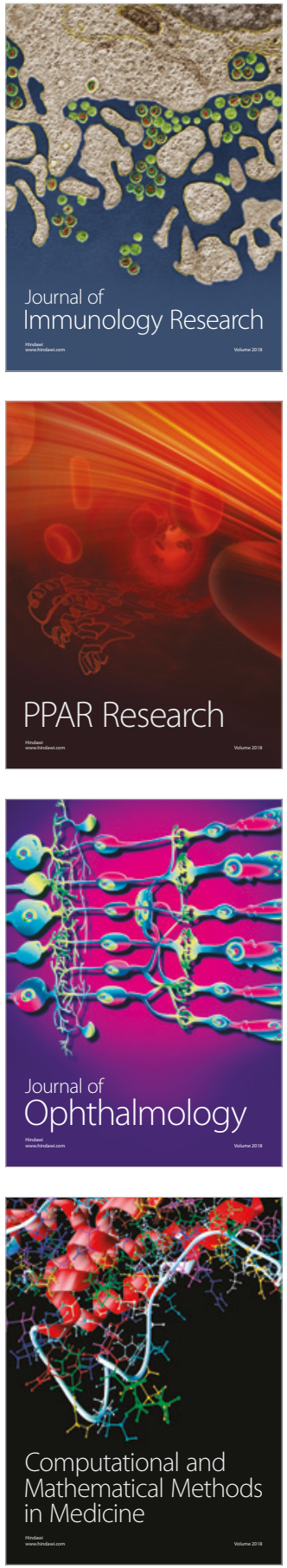

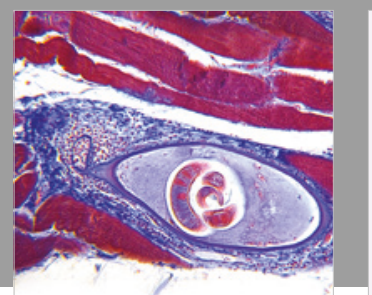

Gastroenterology Research and Practice

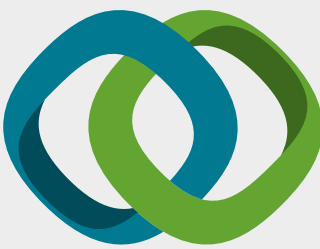

\section{Hindawi}

Submit your manuscripts at

www.hindawi.com
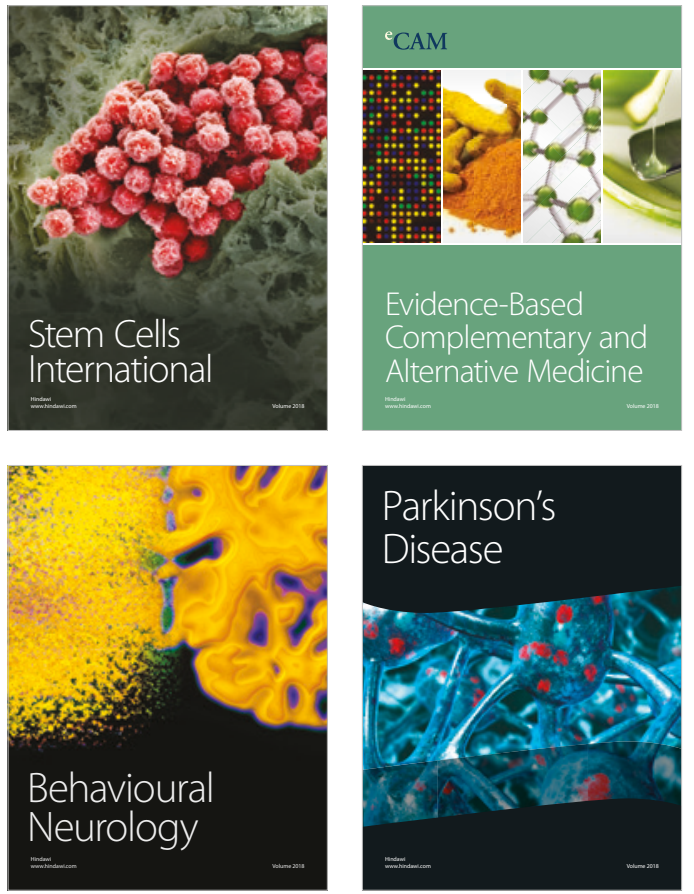

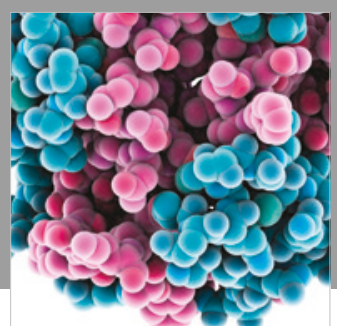

ournal of

Diabetes Research

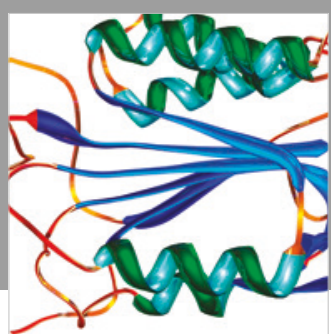

Disease Markers
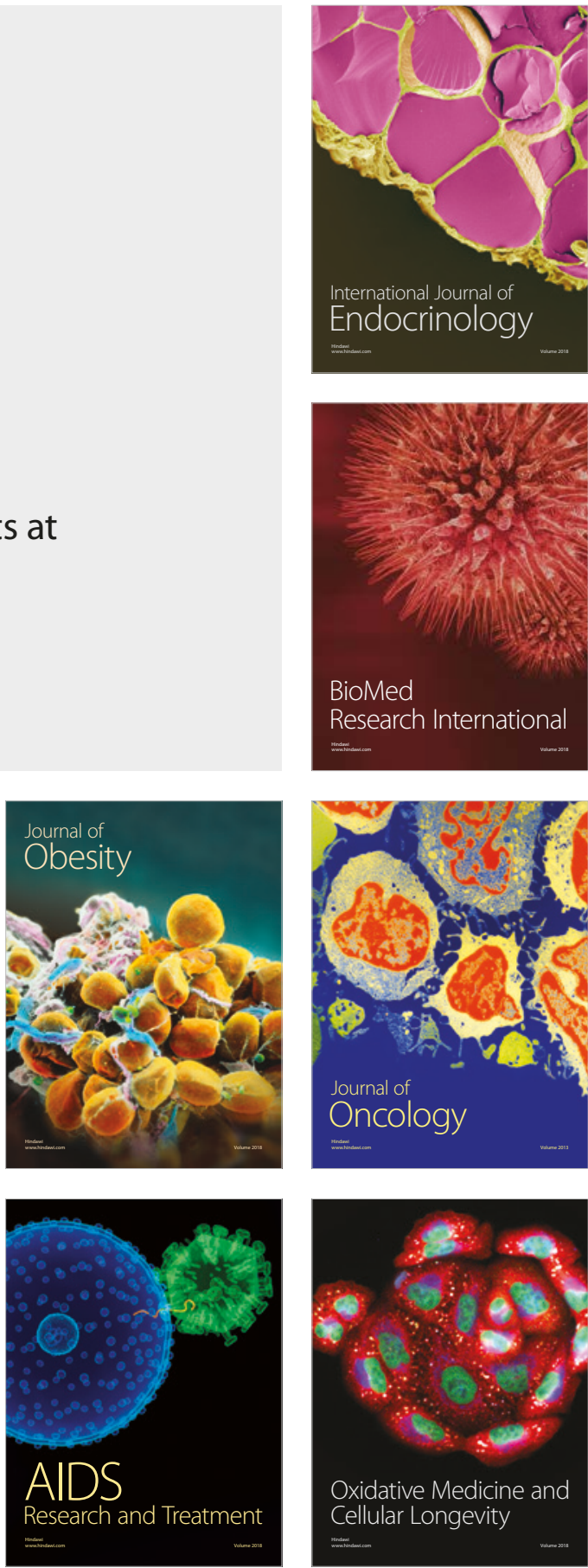